\title{
Engaging Patient: Let's Talk about How Health Providers Can Do it Right
}

\author{
Grilo AM* and Santos MC \\ Research Center for Psychology Science, ESTeSL - School of Health Tecnology, Polytechnic Institute of Lisbon, Portugal
}

Submission: September 26, 2017; Published: October 23, 2017

*Corresponding author: Grilo AM, School of Health Tecnology, Polytechnic Institute of Lisbon, Portugal, Email: ana.grilo@estesl.ipl.pt

\section{Opinion}

Engaging patients and families in patient care has been called a necessary condition for the redesign of the health care system and may be perceived as mandatory for the 19th century delivery of health care. For example, progresses in surgical care made possible for more patients to survive severe clinical conditions, but most of these patients are been discharged sooner and sicker from hospitals [1-3] transferring the responsibility for patient care to patient's families. Further the development of life support technology increased the possibility for patients to remain at home despite been in a fragile health condition or requiring constant care. To respond to these demands of care patients and their families must be empowered and work in straight collaboration with the healthcare providers. Patient engagement has been defined by WHO [4] as the process of building the capacity of patients, families, careers, as well as health care providers, to facilitate and support the active involvement of patients in their own care, in order to enhance safety, quality and people centeredness of health care service delivery [2]. Engagement involves partnership which demands mutual trust, honesty, respect and loyalty as well as a strong attitude towards sharing information, decisions and responsibilities [3] and is focused and organized around the health needs and expectations of people and communities rather than on diseases [4]. Therefore, levels of patient engagement must be adequate to each patient and to each situation. Carman [5] proposed a model for patient engagement that was developed in conjunction with patient and family representatives. In this model engagement is perceived in a continuum that is defined by how much the information flows between patient and health providers, how involved patient are in shared power and responsibilities, in decisions making in health organization and in policy making. Factors influencing the adequate level of engagement include individual factors i.e. patient's vulnerability (e.g. cognitive impairments; health status), level of education and health literacy, wishes and motivation to be involved [6]. Nevertheless, those are not reasons to deny patients and families the opportunity to be part of patient care. There is a growing evidence that engagement is associated with improvement in an extensive range of health related outcomes $[7,8]$ reduce of health costs, quality of life and patient safety [9]. Despite the recognition of patient engagement as a value for the quality of care, there`s still a long and challenging way to run to allow that most patients become activelyengaged in managing their own health (for example, more than half of Americans are not active involved in their health care $[10,11]$. In fact, many health providers underused strategies to promote patient engagement [11]. The most common health-provider barriers include:

a) Concerns around hierarchies, power imbalances and control [12,13].

b) Conflict of attitudes, toward the model of care, among the health team members [14].

c) Conflict of attitudes and values, toward the model of care, between health care providers and the organizational policy [13].

d) Insufficient training in patient engagement $[13,15]$.

e) Fear of change [13].

Actually, patient's engagement is a challenge that comprises many efforts for health providers. Some of these efforts demand attitudes and behaviors changes, that are not easy to modify and that involve motivation, education, and time. Patient engagement requires health professionals, organizations and policies.

a) Create a clear opportunity for engagement.

b) Make it clear that they welcome engagement.

c) Provide the support that people need to engage [5].

In addition, health providers need to belief that most patients want and can participated in all decisions about their health care. Second health professionals should recognize patient-centered approach as an essential feature that allow an ongoing partnership and embrace their expertise and patients and families' strengths [11]. To ensure that the benefits of engagement patients are entirely harnessed, proactive strategies 
should be used. However before adopting these strategies health providers must acknowledge patients' health and emotional condition, resources and motivation. The strategies that have been shown to be more effective are [16-18].

a) Encourage patients to tell their story. Use open-ended questions to encourage patients to talk about illness, their experience, concerns, feelings, needs, values, preferences.

b) Show interest in patients experience and availability. Incorporating patient's opinions, values and needs in treatment plans.

c) Use non-judgmental listening.

d) Summarizes patient narrative to verify understanding.

e) Share health information using 7Cs: clear, concrete, concise, correct, coherent, complete and courteous language. Complete medical information with examples, images or case stories.

f) Discuss medical records with patient and family.

g) Encourage patients to ask questions about their diagnosis and treatment options.

h) Check understanding by asking patients feedback or teach back.

i) Use negotiation; showing respect about patient's needs, expectations and objectives (avoid direct advice and impositions).

j) Ask about potential difficulties to following the program.

k) Reinforce patients for reaching small successes.

l) Communicate with patients by email or phone to follow treatment plan or check what progress has been made on health/disease.

m) Disclosure when errors occurs (sentinel events or other incidents like unexpected treatment outcome). Apologize and provide information.

Considerable work is required to ensure that health providers can and want to use these strategies. By adopting them health providers can support patient-centered care and meet patient and family's requirements to allowed patient engagement. As Parent et al. [19] defends empowerment of the patient cannot be mandatory but should be promoted and developed. To do so, a focus should be put on health provider's attitudes and values concerning the model of care as well as enhanced communication skills training that support patient engagement [20].

References

1. Aranda JM, Johnson JW, Conti JB (2009) Current trends in heart failure readmission rates: analysis of Medicare data. Clin Cardiol 32(1): 4752.
2. (2016) World Health Organization. Patient Engagement: Technical Series on Safer Primary Care. Geneva, Switzerland.

3. Mittler JN, Martsolf GR, Telenko SJ, Scanlon DP (2013) Making sense of consumer engagement initiatives to improve health and health care: a conceptual framework to guide policy and practice. Milbank Q 91(1): 37-77.

4. World Health Organization. Health Systems Strengthening. Glossary, Geneva, Switzerland.

5. Carman K, Dardess P, Maurer M, Sofaer S, Adams K, et al. (2013) Patient and family engagement: a framework for understanding the elements and developing interventions and policies. Health Aff 32(2): 223-231.

6. Maurer M, Dardess P, Carman KL, Frazier K, Smeeding L, et al. (2012) Guide to patient and family engagement: environmental scan report. Agency for Healthcare Research and Quality.

7. Greene J, Hibbard J (2011) Why does patient activation matter? An examination of the relationships between patient activation and health-related outcomes. J Gen Inern 27(5): 520-526.

8. Simmons LA, Wolever R, Bechard E, Snyderman R (2014) Patient engagement as a risk factor in personalized health care: a systematic review of the literature on chronic disease. Genome Med 6(2): 16-28.

9. Coulter A, Ellins J (2007) Effectiveness of strategies for informing, educating, and involving patients. BMJ 335(7609): 24-27.

10. Hibbard JH, Green J (2013) What the evidence shows about patient activation: better health outcomes and care experiences; fewer data on costs. Health Aff 32(2): 2207-2214.

11. (2016) The Joint Commission Patient, Busting the Myths about Engaging Patients and Families in Patient Safety, Illinois, USA.

12. Henderson S (2003) Power imbalance between nurses and patients: a potential inhibitor of partnership in care. J Clin Nurs 12(4): 501-550.

13. Bear RA, Stockie S (2014) Patient engagement and patient-centered care in the management of advanced chronic kidney disease and chronic kidney failure. Can J Kidney Health Dis 1: 24.

14. Bettes BA, Coleman VH, Zinberg S (2007) Cesarean delivery on maternal request: obstetrician-gynecologists' knowledge, perception, and practice patterns. Obstet Gynecol 109(1): 57-66.

15. Bergeson SC, Dean JD (2006) A systems approach to patient-centered care. JAMA 296(23): 2848-2851.

16. Kurtz SM, Silverman JD, Draper J (2004) Teaching and learning communication skills in medicine, $\left(2^{\text {nd }} e d n\right)$, Oxford, Radcliffe Medical Press, UK.

17. Patient-Centered Communication in Cancer care: Promoting Healing and Reducing Suffering, National Cancer Institute, NIH Publication.

18. McDonald KM, Bryce CL, Graber ML (2013) The patient is in: patient involvement strategies for diagnostic error mitigation. BMJ Qual Saf 22(Suppl 2): ii33-ii39.

19. Pernet A, Mollo V, Bibault JE, Giraud P (2016) Evaluation of patients' engagement in radiation therapy safety. CancerRadiother 20(8): 765767.

20. Grilo AM, Santos M, Gomes A, Rita J (2017) Promoting PatientCentered Care in Chronic Disease (p.51-70). In: Sayligil O (Ed.), Patient Centered Medicine. Croatia, InTech, DOI: 10.5772/63030. 
(C) This work is licensed under Creative BY Commons Attribution 4.0 License
Your next submission with Juniper Publishers will reach you the below assets

- Quality Editorial service

- Swift Peer Review

- Reprints availability

- E-prints Service

- Manuscript Podcast for convenient understanding

- Global attainment for your research

- Manuscript accessibility in different formats

( Pdf, E-pub, Full Text, Audio)

- Unceasing customer service

Track the below URL for one-step submission https://juniperpublishers.com/online-submission.php 